\title{
Design Thinking under Internet Shock
}

\author{
Qian Anming ${ }^{1,2}$; Li Zhe ${ }^{2}$ \\ ${ }^{1}$ Art College Soochow University, Suzhou Jiangsu 215123; \\ ${ }^{2}$ Textile Engineering \& Art College, Anhui Agricultural University, Hefei Anhui 230036 \\ 346591653@163.com
}

Keywords: The Internet Era; Design thinking; Design revolution; Design sociology; Design education

\begin{abstract}
Human beings have entered the Internet Age; shock of the new era has brought thinking revolution. This paper analyzes the basic features of the Internet Age from the perspective of sociology and design theory, analyzes the development relations among handicraft, industrial design and information design, illustrates the innovative features of design thinking of the Internet Age, reveals and discloses the revolution trend of the future design.
\end{abstract}

\section{Introduction}

Since the birth of Internet, the society, economy, culture and even individual life have gone through huge changes. Just as the reform function of industrial revolution and industrial production is not only embodied in industrial upgrade, the social influence of the Internet is also all-round. Such reform even triggers the experts' and the masses' thinking of the existence value of 'making a living in the city or living a good life in the city'. Based on researches like these, this paper makes gradual statements in three aspects and from the perspective of sociology and design science.

\section{Internet Shock}

Internet shock of the contemporary social productivity and production relations is greater than the influence of any previous production tools. The steam engine reformed by Watt is widely applied on the three islands of Britain. Britain first had the industrial revolution. Edison lighted charcoal lamp and set up the American grid. Hence the newborn United States rapidly became the backbone of the second industrial revolution, whose status of economic hegemony and super power remains till today. After the above-mentioned two industrial revolutions, different from the former isolation, China realized whole-functional connection to the Internet on April 20, 1994, thus becoming the $77^{\text {th }}$ country connected to the international Internet. Within two years after Yahoo entered into the daily life of Americans, Zhang Chaoyang graduated from MIT and returned to our country. With the venture capital of 225,000 dollars provided by his pioneering supervisor Nicholas Negroponte, he created Sohu, a classification information website with similar functions in Beijing. 'For Chinese, Nicholas Negroponte is the torchbearer of the Internet. Digitalized survival opened the Internet world for Chinese and aroused people's enthusiasm of exploring the Internet ${ }^{[2] .}$

Actually, internet not only functions as an equipment platform; it is also productivity itself. Take the example of communications and information revolution as the example. Traditional telecommunication simulation signal is switched and transmitted through the small-scale base 
stations just like the beacon tower; it can only transmit voice and SMS within a small scope, with worse communication ability and communication quality. 3G, 4G, 5G and more advanced Internet innovative technologies based on international communication satellite in the future made the telecommunications access transmit more high-quality simulation communications. Lossless data compression technologies can be adopted to directly transfer the visualized and multi-media materials, such as text, image and dynamic images etc. This digitalized revolution eliminated the functional telephone. Intelligent telephone no longer exists as the single voice communication tool, but becomes an indispensable tool of people's daily life and digitalized PDA in the real sense. PAD between telephone and PC obscures the application boundaries of the two types of tools and expanded the application conditions of the two types of tools. Work and recreation of people can be operated on the same digitalized terminal simultaneously and realized 'cloud' long-distance synchronization.

\section{New Ecology of Social Life}

The original work prototype of Internet is the fishing net; 'decentralization' is its main feature. People gather together due to network. Hence the traditional relations among relatives and work partners have gone through great shocks. Soho and mobile office are no longer fashionable words, but are the current situation of transformation. Through the information communications of Internet, people can flee the big cities and lattices and creatively finish multiple businesses.

On November 11, 2015, the 24-hour turnover of T-mall reached 91.217 billion RMB, among which the total sum of wireless turnover reached 62.642 billion RMB, taking up $68.68 \%$, far higher than the turnover on November 11, 2014, which reached 57.1 billion RMB. It is also close to the total sum of the turnover of the former three years. 'Double 11' of T-mall in 2012 created the turnover of 19.1 billion...The number in 2013 was even more startling-35.02 billion RMB ${ }^{[2]}$. The appearance of e-business platforms such as Amazon, Ebay, Alibaba, Dangdang and JD has greatly changed the marketing ecology of the book stores and supermarkets. The industrial structures, channels and type of business of the traditional business have been thus influenced, so they must make according adjustments and keep perfecting in reform, which is the general trend of the ecological development of modern business.

For common users of Internet, besides the commodity trade, emotional demands in their life seem more urgent. The hierarchy theory of Abraham Harold Maslow, the social psychologist, does not need to be repeated here. Facebook in America, QQ and WeChat of Tencent developed rapidly, the momentum of which just increased. Hence we can feel how people need the intercourse in network space. The natural momentum of social demands changed the relation between traditional mass media and individual audience and strengthened the methods and means of stereo intercourse. At present, besides face-to-face communication, people can also have online chats through data collection of the camera lens and based on the real-time data transmission of the network. People can also carry out immediate discussion concerning some major issue with the domestic and foreign colleagues, rather than wait for participants from different places who hurry to order the air tickets and get back to the conference.

The law of the unity and opposites reminds us that the application of internet brings some favorable aspects in terms of production tools, productivity and reform of production relations,; however, its destruction and safety risk also needs emphasizing. Take the example of network games; 
such network application that can be applied to multiple devices attracts people much more than the electronic games in the 1980s and 1990s do, but it also wastes more time and energy. The profit-making game bars and net bars through offline operation have limitations of various objective conditions after all; people need to play the games in the actual places. After common families connect the digital terminal of the Internet, various games can be easily acquired to have on-line competition. They can solve the basic needs without going outside. 'People who like staying at home' are more likely to be engaged in the novel network world and be separated with the real world ${ }^{[4]}$,

For children and adolescents who have not reached mental maturity, the negative aspects of intelligent game products are especially huge. The hardware and software of traditional personal computer has certain professional skills, such as mouse clicking and keyboard clicking etc. However, application of tablet PC and telephone is easy, which does not require special training. Infants can play with the square 'digital magic tablet' for a whole day, hence they neglect the mechanic toys, Lego and fuzzy toys. Education experts notice that if children contact electronic devices and network applications too early, it is unfavorable for the personal cognitive and intelligence development. The concrete influence details are not mentioned here. Children do not get good sleep; long-term game playing must do harm to visual impairment. While bringing the convenience of remote information communication, Internet also strengthens the sense of loneliness and isolation of individuals.

\section{Innovative Thinking of Internet Age}

Internet creates new ecological civilization and causes new design thinking. 'The significance of creation is to break through the shackles of the existing things and form the design conception with unique and novel brand-new concepts or forms ${ }^{[5]}$.' The concept of creative design thinking of people also turned from the age of agricultural civilization age and industrial civilization age to (information) Internet age. The design of the agriculture civilization is called 'pre-design age' in the eyes of the modern design historians. Making and sales of pottery, furniture, daily goods is often independently finished by handicraftsman or created by the small-scale shops. The handicraft works of this phase have good texture and unique personality, but less strong systematicness. However, in the industrialized daily goods of batch production, the individual differences are eliminated. In terms of judgement of art aesthetics, handicraft products are characteristic of individuation and the milk of human kindness. However, from the perspective of economics and technologies, it is easy to see that the productivity and efficiency of manual shops is quite low, thus leading to different qualities of end products.

Different from the condition that the steam engine and power started from a country, then was gradually popularized to other countries and regions after the technology was matured, at the birth of Internet, it took connection of the globe as the mission. The inventor of this technique Tim Berners-Lee even gave up patent application and claimed that his invention belonged to everyone (this is for everyone). The time for China to be connected to the international Internet did not fall much behind that of the developed countries. Development of international Internet accords with the global tendency; the global market is further expanded. The complete design information model, the global transmission of big data documents, application of virtual reality technique provided feasible techniques and methods for the scheme of modern design. Through the low-cost 3D printing technique, it can realize globalized coordinated innovation, design, production, manufacturing, business outsourcing, network marketing and online financial payment etc. A series of business 
procedures can be simplified accordingly. The empathy design that focuses on users and pays attention to individuation is also introduced into the early concept design procedures ${ }^{[6]}$.

Innovative design of the Internet Age has the features of the industrial age and the new features of digitalization and intelligence. To some extent, it can even make the traditional handicraft revive. 'Design art in the digital age also needs according innovation and recreation of the thinking mode ${ }^{[7]}$.' In this Marker movement of Internet, pioneers have become digital artists through 3D printing techniques to create the custom-made products with low costs, individuality and multiple types at their will. Chris Anderson ${ }^{[8]}$, author of The Long Tail and Free, gave up Study Theory and speech, resigned from the chief editor post of Wired and then acts as CEO of 3D Robotics. He proves the possibility of prospective theory with the method of industrial practice.

'Any practical activities such as creation, invention, innovation and discovery are associated with the uniqueness of thinking ${ }^{[9]}$.' The impact of internet is multi-faceted In terms of product design of Internet Age, the development thinking of new products is no longer limited to the traditional process: to have a trial sale in the local market; to enter the domestic market after the product matures; finally to expand to the overseas market. Internet has the purpose of international and dispersed communication at the beginning of birth. The new product design of Internet Age carries out researched based on global market from the beginning; marketing channel can be directly conducted in the 'earth village'. Through telephone translation software such as Google and Baidu, the language obstacles among netizens are eliminated. 'The tow of babel' may be built in 'cloud'

\section{Summary}

Internet, as a revolutionary production tool, can be compared to the steam engine of the first industrial revolution. As the important activist new energy and social boost power, Internet may equal to the electric power and nuclear power of the second industrial revolution. Internet is also the new production tool, productivity and production relations of the third industrial revolution. Internet is the information carrier, just like the highway carrying billions of vehicles. Only when digital terminal operate on the smooth information highway can the monomer have the opportunity to exert great work efficiency. In face of the shock of Internet Age, 'to construct our country from a large network country to a strong network country' has become the development strategy of our country. We, at the new phase of historical development, judge and analyze the design thinking of the new age. We just make orientation thinking so as to arouse the attention of the design theorists, design historians and thinking research experts.

The design thinking of the Internet Age is the new phase of innovative thinking evolution. Interaction among people and things has the reality possibility. Intelligent grid connects the electrical equipment in each building. Construction and share of digitalized information resources and the design thinking of the Internet Age is bound to jump out of the shatters of the personal talent theory. Besides crowdfunding capitals, people can also crowdfund wisdom and novel ideas so as to boost the realization of 'global brain' and 'earth brain' envisaged by Kevin Kelly. 'As the moon rises above the sea, we share the same time though we are far apart.' Zhang Jiuling, the poet in the Tang Dynasty, watched the limitless vast sea and wrote this poem. He expressed his feelings through the moon in the sky and imagined the beautiful time spent with his faraway relatives. Popularization of Internet technology makes the wish of the ancient people become a reality. The sail of the Internet just begins; there is still a long way ahead. 


\section{Acknowledgements}

This thesis belongs to the project of quality engineering of Anhui Agricultural University: Reform Research of Examination Mode of Non-standard Key (Project No.: AHAU2015-37-73).

\section{References}

[1] Lu Ming. Making a Living in the City or Living a Good Life in the City[J]. Journal of Shanghai Jiao Tong University: Philosophy and Social Sciences Edition, 2014(4): 10-16.

[2] Wu Xiaobo. Commercial War: E-commerce Era[M]. Wuhan: Hubei Education Press 2014: 226.

[3] Liao Jun. Visual Art Thought[M]. Beijing: China Textile \& Apparel Press, 2013: 19.

[4] Qian Anming, Wu Rong. Clothing Design Introspection besides Fashion[J]. Journal of Anhui Agricultural University: Social Sciences Edition, 2010, 01: 132-135.

[5] Qian Anming. Research of Art Design Thinking Methods[D]. Hefei: Architecture and Art College of HeFei University of Technology, 2007.

[6] Zhang Jianing. Application of Emphatic Design Methods in Product Design[J]. Packaging Engineering, 2015: 24: 144-147.

[7] Qian Anming. Research of Art Thoughts and Innovative Methods of Digital Design[D]. Shanghai: Clothing Art Design College of Donghua University, 2009.

[8] Leading team of the Internet Age. The Internet Age[M]. Beijing: Beijing United Publishing Co., Ltd, 2015: 80.

[9] Lu Xiaobiao, Qian Anming. Design Thinking[M]. Hefei: Hefei University of Technology Press, Hefei, 2006:11. 